\title{
Effect of using recycled waste glass coarse aggregates on the hydrodynamic abrasion resistance of concrete
}

DOI:

10.1016/j.conbuildmat.2020.121177

\section{Document Version}

Accepted author manuscript

Link to publication record in Manchester Research Explorer

\section{Citation for published version (APA):}

Omoding, N., Cunningham, L., \& Lane-Serff, G. F. (2021). Effect of using recycled waste glass coarse aggregates on the hydrodynamic abrasion resistance of concrete. Construction and Building Materials, 268, [121177]. https://doi.org/10.1016/j.conbuildmat.2020.121177

\section{Published in:}

Construction and Building Materials

\section{Citing this paper}

Please note that where the full-text provided on Manchester Research Explorer is the Author Accepted Manuscript or Proof version this may differ from the final Published version. If citing, it is advised that you check and use the publisher's definitive version.

\section{General rights}

Copyright and moral rights for the publications made accessible in the Research Explorer are retained by the authors and/or other copyright owners and it is a condition of accessing publications that users recognise and abide by the legal requirements associated with these rights.

\section{Takedown policy}

If you believe that this document breaches copyright please refer to the University of Manchester's Takedown Procedures [http://man.ac.uk/04Y6Bo] or contact uml.scholarlycommunications@manchester.ac.uk providing relevant details, so we can investigate your claim.

\section{OPEN ACCESS}



HYDRODYNAMIC ABRASION RESISTANCE OF CONCRETE

\section{ABSTRACT}

This experimental study is aimed at evaluating the hydrodynamic abrasion resistance of concrete produced with recycled waste glass as coarse aggregates. The underwater (ASTM C1138) method is used to test concretes containing $0 \%, 12.5 \%, 25 \%, 50 \%$ and $100 \%$ glass aggregates as replacement for natural coarse aggregates. To benchmark performance, the abrasion resistance of glass-aggregate concretes is compared with that of a high-strength concrete mixture typically used in coastal defences where abrasion resistance is critical. Further comparison is made with a general application concrete mixture containing crushed limestone coarse aggregates. At 95\% confidence, results of the KruskalWallis test show that the use of recycled waste glass as coarse aggregates in concrete at contents of up to $25 \%$ does not significantly affect its abrasion resistance. When compared with the typical highstrength mixture with proven field performance, the results of the Kruskal-Wallis test at 95\% confidence indicated that abrasion resistance at glass aggregate replacement levels of up to $25 \%$ was not significantly different. Concrete produced with $100 \%$ recycled waste glass coarse aggregates had comparable abrasion resistance with that produced with 100\% crushed limestone coarse aggregates. Additionally, there was a stronger and significant dependence of the abrasion resistance of glassaggregate concretes on tensile splitting strength in comparison to both compressive strength and modulus of elasticity.

\section{Keywords}

Recycled waste glass; abrasion resistance; concrete aggregates; hydrodynamic abrasion; environmental sustainability.

\section{INTRODUCTION}

It is increasingly becoming difficult to sustainably manage the growing amount of glass waste around the world. For instance, the total glass waste output of the 28 countries of the European Union (EU) in 2006 increased by 22\% in 2016 to 19 million tonnes, and of this, the United Kingdom (UK) contributed about $15 \%$ [1]. With the UK recycling/recovery rate of about $67.6 \%$ in 2017 [2], it is clear that a 
considerable proportion of glass waste was disposed of to the environment. Statistics from the United States are even worse because out of the 11.38 million tonnes of glass waste generated in 2017, over $60 \%$ was landfilled [3]. The high percentages of unrecovered/unrecycled waste glass present a significant opportunity for reuse and the corresponding reduction in negative environmental effects.

One of the sustainable strategies for dealing with glass waste is to recycle it for use in concrete. Hydraulic structures such as coastal defences, marine outfalls, hydro-electric dam components, etc. provide an opportunity for large-scale consumption of waste glass. However, the concrete specification for these structures is often controlled by their exposure conditions due to the prevalence of a wear phenomenon termed as hydrodynamic abrasion or abrasion-erosion [4]. Hydrodynamic abrasion of concrete refers to the mechanical disintegration of its surface due to the action of waterborne solids [4]. The resulting surface damage is often severe when concrete surfaces are attacked by hard and coarsegrained sediments e.g. pebbles and cobbles transported at velocity. Figure 1 shows stepped concrete revetment armour units at Cleveleys on the Fylde Peninsula of the UK abraded by shingle (rounded beach pebbles). This site is arguably one of the most abrasive coastal environments in the UK where abrasion resistance can govern the concrete specification [5]. In fact, the abraded concrete surfaces in Figure 1 were constructed with a high-strength mixture designed to meet the requirements of BS 63491-4 [6] for abrasive exposure conditions. As such, the concrete had a cube compressive strength of $64.6(>50) \mathrm{MPa}$, water to binder ratio of $0.436(<0.45)$, binder content of $440(>350) \mathrm{kg} / \mathrm{m}^{3}$ and used abrasion-resistant aggregates [5, 6]. As is standard practice in pre-cast concrete coastal defence elements, the units were cast face down such that the surface exposed to abrasion exhibited increased concrete density and a high-quality surface finish [7, 8]. Field observations indicate that in general, the mixture used has so far shown a good level of abrasion resistance since the units were installed around 15 years ago [5].

ACl Committee 207 Report [4] also enumerates examples of other concrete hydraulic structures severely damaged by abrasion hence requiring costly repairs to maintain serviceability and reduce safety risks. The selection of appropriate concrete materials for structures located in abrasive environments therefore requires their hydrodynamic abrasion resistance to be first evaluated. Hydrodynamic abrasion resistance can be tested using the ASTM C1138 [9] test method and this has been used extensively in studies focussed on the identification of factors that influence concrete abrasion resistance as summarised in a recent review by the authors [10]. 


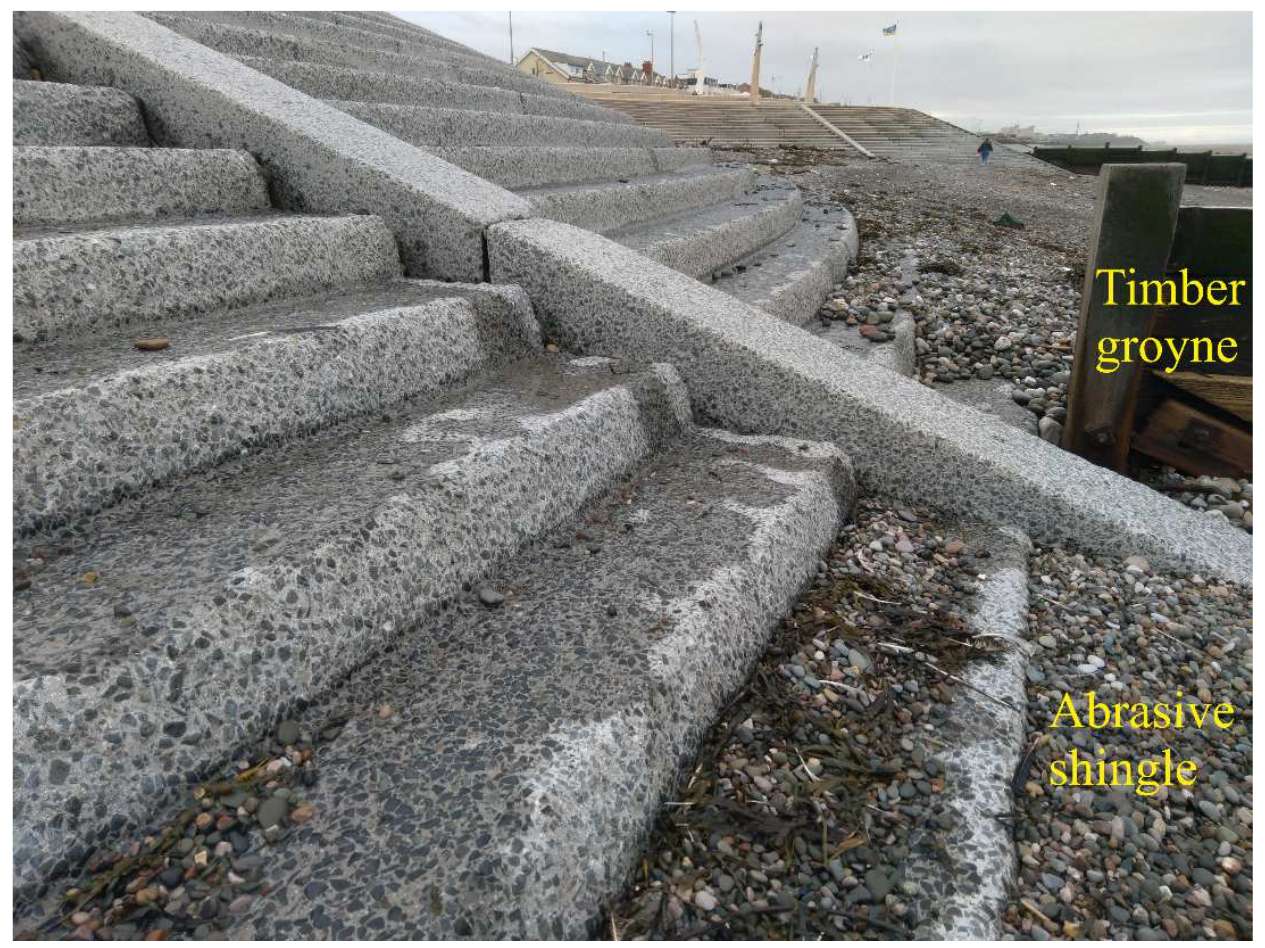

Figure 1-Abraded stepped revetment armour units at Cleveleys on the UK's Fylde Coast.

The use of recycled glass waste as a concrete aggregate has attracted considerable research interest with a number of studies investigating its general use as a replacement for either natural fine aggregates only, natural coarse aggregates only or both natural fine and coarse aggregates [11-14]. The replacement of proportions of natural aggregates is more justified by the fact that they often occupy at least $75 \%$ of the total concrete volume [15]. Topçu and Canbaz [11] investigated the performance of concretes mixtures containing $0 \%, 15 \%, 30 \%, 45 \%$ and $60 \%$ recycled waste glass aggregates with compressive strengths that varied from 12.4 to $23.5 \mathrm{MPa}$. The natural fine aggregate used was river sand at a content of $647 \mathrm{~kg} / \mathrm{m}^{3}$ while crushed natural coarse aggregates obtained from a calcareous rock were used in quantities of $561 \mathrm{~kg} / \mathrm{m}^{3}(4-16 \mathrm{~mm})$ and $559 \mathrm{~kg} / \mathrm{m}^{3}(16-32 \mathrm{~mm})$. The waste glass aggregates were formed from crushed coloured soda bottles with a grading of 4-16 $\mathrm{mm}$ and introduced to replace the corresponding particle size range of natural coarse aggregates. The cement used (350 $\mathrm{kg} / \mathrm{m}^{3}$ ) was Portland-composite cement (PKÇ/B 32.5 R) that complied with the requirements of TS $12143[16]$ and the water to cement ratio was maintained at 0.54 . All the samples were cured in limesaturated water, and 3 specimens were used for each test at the expiry of the 28-day curing period. The research concluded that whilst there were cost and environmental benefits in using waste glass aggregates, especially at high contents, its addition to concrete reduces strength (compressive, indirect 
tensile and flexural), dynamic modulus of elasticity and surface hardness. The study also highlighted the potential harmful effects of alkali-silica reaction (ASR) in concretes with waste glass aggregates. Some studies have however shown the detrimental effects of ASR in glass-aggregate concretes can be mitigated by use of ground granulated blast-furnace slag, metakaolin [17] and fly ash [18].

Terro [12] tested the cube compressive strengths of concretes in which $0 \%, 10 \%, 25 \%, 50 \%$ and $100 \%$ of natural aggregates were replaced with crushed-bottle glass with sharp edges at both ambient and elevated temperatures. The natural coarse aggregates in sizes of 10 and $19 \mathrm{~mm}$ were produced from gabbro while the natural fine aggregate was desert sand. The control mixture ( $0 \%$ glass) had a water to cement ratio and compressive strength of 0.48 and $40 \mathrm{MPa}$ respectively. Its cement, natural fine and coarse aggregate contents were $416.6 \mathrm{~kg} / \mathrm{m}^{3}, 673.4 \mathrm{~kg} / \mathrm{m}^{3}$ and $1107.1 \mathrm{~kg} / \mathrm{m}^{3}$ respectively, and an unspecified admixture was also added at a dose of $2.7 \mathrm{~kg} / \mathrm{m}^{3}$. In the investigation by Terro [12], the replacement was carried out for natural fine aggregates, natural coarse aggregates and both natural fine and coarse aggregates for temperatures varying from 20 to $700{ }^{\circ} \mathrm{C}$. The study reported that increased amount of waste glass aggregates in concrete reduced its compressive strength at both ambient and elevated temperatures regardless of whether natural fine aggregates, natural coarse aggregates or both natural fine and coarse aggregates were replaced. Furthermore, it was shown that concrete mixtures with fine glass replacements performed better than those with coarse and combined fine and coarse waste glass aggregate replacements.

Serpa et al. [13] also investigated the mechanical properties of concrete with crushed fine (passing 4 $\mathrm{mm}$ sieve), coarse (4-11.2 $\mathrm{mm})$ and both fine and coarse waste glass aggregates. The performance of glass-aggregate concretes was compared with that of a control mixture with limestone aggregates of $22.4 \mathrm{~mm}$ maximum particle size. The concrete mixtures tested had water to cement ratios that varied from 0.55 to 0.58 to maintain the slump within $10 \mathrm{~mm}$ while the cement type used was CEM II A-L 42.5 [19]. The waste glass aggregates were obtained from building windows and car windscreens at replacement levels of $5 \%, 10 \%$, and $20 \%$. The results showed that the use of waste glass aggregates reduced both compressive and tensile strengths and the degree of reduction suffered depended on both the replacement proportion and maximum size of waste glass aggregates. In contrast, there was no discernible effect on the modulus of elasticity while abrasion resistance measured using the Böhme method [20], which is not a hydrodynamic test, was reported to improve when recycled coarse waste glass aggregates were incorporated in concrete. 
1 It is evident that the effect of recycled waste glass on the basic mechanical properties of concrete is

2 fairly well understood. However, none of the past studies have investigated the resistance of glass-

3

4

5

6

7

8

9 aggregate concretes to hydrodynamic abrasion, which is a key requirement for hydraulic structures. The objective of this study is to evaluate the effect of the replacement of various proportions of natural coarse aggregates with recycled waste glass aggregates on the hydrodynamic abrasion resistance of the resultant concrete. As a means of benchmarking, the abrasion resistance of glass-aggregate concretes is compared with that of the mixture used for the existing coastal defences at Cleveleys. Thereafter, the abrasion resistance of concrete produced with recycled waste glass coarse aggregate only is compared to that of a mixture with comparatively softer limestone which is one of the most commonly used coarse aggregates in general concrete applications including coastal defences described in $[7,8]$. Finally, the relations between the hydrodynamic abrasion resistances of glassaggregate concretes with their basic mechanical properties are assessed.

\section{EXPERIMENTAL PLAN}

\subsection{Materials}

\subsubsection{Coarse aggregates}

This investigation used both natural and recycled waste glass coarse aggregates. The natural coarse aggregates selected were: bunter quartzite, crushed limestone and andesite hornfels. The hornfels aggregate used is also known commercially in the UK as Shap blue granite or simply Shap blue and was used in the existing coastal defences at Cleveleys. The bunter quartzite and limestone coarse aggregates complied with grading requirements of BS EN 12620 [21] for $10 \mathrm{~mm}$ maximum particle size whilst the hornfels was in accordance with the specifications for $20 \mathrm{~mm}$ maximum particle size. The mixed-colour recycled waste glass aggregates were supplied by Viridor in Sheffield (UK) and were predominated by green-coloured glass (77.6\%). The amber, clear and other colours constituted $12.3 \%$, $9.9 \%$ and $0.2 \%$ respectively. The glass-aggregate particles were generally of poor (flaky) shape with a vast majority retaining the thickness and surface texture of the original items from which they were derived. However, the waste glass aggregates used were free of sharp edges thus easily handled without the need for heavy-duty hand gloves. The Mohs hardness index for both quartzite and hornfels coarse aggregates was 7 while indices of glass and limestone were 5.5 and 3.5 respectively. The representative samples of waste glass and hornfels coarse aggregates are shown in Figure 2. 


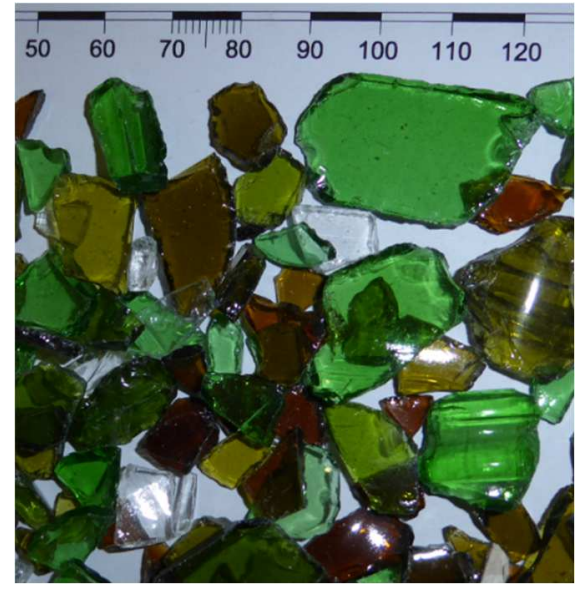

(a)

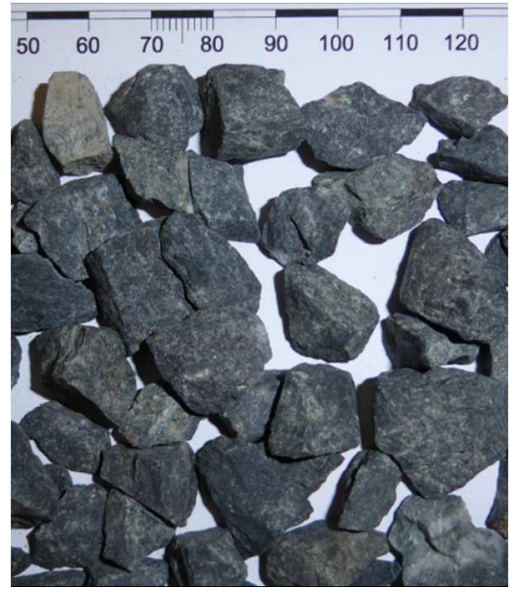

(b)

Figure 2- (a) Recycled waste glass aggregates; (b) Crushed hornfels aggregates

3 The relative densities and water absorption of the coarse aggregates used are shown in Table 1.

\begin{tabular}{|l|c|c|}
\hline Aggregate & Relative density & $\begin{array}{c}\text { Water } \\
\text { absorption (\%) }\end{array}$ \\
\hline Recycled waste glass & 2.49 & 0.4 \\
\hline Bunter quartzite & 2.59 & 0.6 \\
\hline Crushed andesite hornfels & 2.84 & 0.5 \\
\hline Crushed limestone & 2.60 & 0.5 \\
\hline
\end{tabular}

Table 1-Relative density and water absorption of coarse aggregates

\subsubsection{Fine aggregates}

The sand used was quartzite complying with the grading requirements of BS EN 12620 [21] for $4 \mathrm{~mm}$ maximum particle size. This was used as the fine aggregate in all concrete mixtures. The relative density and water absorption of the fine aggregate was 2.62 and $0.53 \%$ respectively.

\subsubsection{Cement}

The cement produced according to the requirements of BS EN 197 [19] for CEM II/A-L $42.5 \mathrm{~N}$ was used in the study with exception of the replica of the Cleveleys' concrete mixture in which CEM I 42.5 R was adopted. CEM II/A-L is derived by replacing $6-20 \%$ of Portland cement with fine limestone [19].

\subsubsection{Additional concrete materials}

These materials were included in the study in order to reproduce the concrete mixture used at Cleveleys, and included: silica fume, polypropylene micro-fibres and a mid-range water reducer. Elkem A/S (Norway) supplied the silica fume in slurry form (water: solid ratio of 1:1) whilst the mono-filament micro-fibres and the water reducer were provided by SIKA (UK). The properties of the micro-fibres used are presented in Table 2. 


\begin{tabular}{|l|c|}
\hline Length $(\mathrm{mm})$ & 12 \\
\hline Diameter $(\mu \mathrm{m})$ & 18 \\
\hline Density $\left(\mathrm{kg} / \mathrm{m}^{3}\right)$ & 910 \\
\hline Tensile strength (MPa) & $600-700$ \\
\hline Modulus of elasticity (GPa) & $3-3.5$ \\
\hline Elongation $(\%)$ & $20-25$ \\
\hline
\end{tabular}

\section{Table 2-Properties of polypropylene micro-fibres}

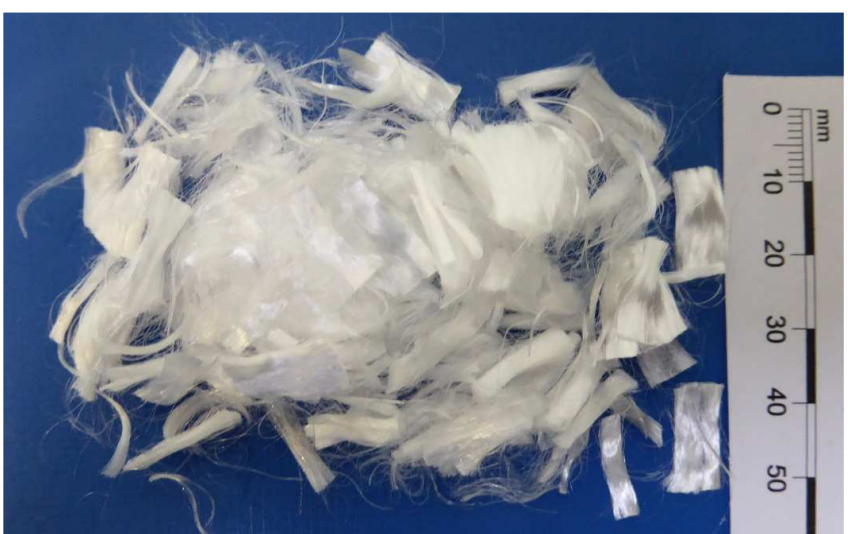

Figure 3-Polypropylene micro-fibres

4

5

6

7

8

9

10

\begin{tabular}{|c|c|c|c|c|c|c|c|c|c|}
\hline \multicolumn{2}{|c|}{ Parameter } & Unit & $\mathrm{RCO}$ & GC12.5 & GC25 & GC50 & GC100 & LCO & SCO \\
\hline \multicolumn{2}{|c|}{ Water/binder ratio } & & 0.52 & 0.52 & 0.52 & 0.52 & 0.52 & 0.52 & 0.44 \\
\hline \multirow[t]{3}{*}{ Binders } & CEM II/A-L $42.5 \mathrm{~N}$ & \multirow{8}{*}{$\mathrm{kg} / \mathrm{m}^{3}$} & 423 & 423 & 423 & 423 & 423 & 423 & - \\
\hline & CEM I 42.5 R & & - & - & - & - & - & - & 400 \\
\hline & Silica fume & & - & - & - & - & - & - & 40 \\
\hline \multicolumn{2}{|c|}{ Fine aggregates } & & 706 & 706 & 706 & 706 & 706 & 706 & 684 \\
\hline \multicolumn{2}{|c|}{ Natural coarse aggregates } & & $976^{a}$ & $854^{a}$ & $732^{a}$ & $488^{a}$ & - & $976^{b}$ & $1106^{c}$ \\
\hline \multicolumn{2}{|c|}{ Recycled waste glass } & & - & 122 & 244 & 488 & 976 & - & - \\
\hline \multicolumn{2}{|c|}{ Polypropylene micro-fibres } & & - & - & - & - & - & - & 0.9 \\
\hline \multicolumn{2}{|c|}{ Mid-range water reducer } & & - & - & - & - & - & - & 3.2 \\
\hline
\end{tabular}

Notes: 1. Superscripts $\mathrm{a}, \mathrm{b}$ and $\mathrm{c}$ denote quartzite, limestone and hornfels CA respectively.

2. The dash in the table means that the material was not used.

11

12

With RCO (0\%) as the reference concrete, the recycled waste glass aggregate contents shown in Table

13

\subsection{Test specimens}

\subsubsection{Concrete mixture design}

The proportions of the concrete mixtures used in the study are shown in Table 3. These were selected to: investigate the effect of waste glass aggregate quantity on concrete abrasion resistance (RC0 and GC12.5 to GC100), compare the resistance of glass-aggregate concretes (GC12.5 to GC100) with that of a mixture typically specified for abrasive field conditions (SCO) and compare the performance of a concrete with $100 \%$ waste glass (GC100) with that produced with limestone (LC0) coarse aggregates.

\section{Table 3-Mixture proportioning for the concretes used}

3 represent replacement levels of 12.5\% (GC12.5), 25\% (GC25), 50\% (GC50) and 100\% (GC100). 
1 Mixture LCO was different from RC0 in that all bunter quartzite coarse aggregates were replaced with

2 limestone. In contrast, the proportions of mixture SCO had no relation with the rest of the mixtures as it

3 was a replica of the mixture used in the coastal defence units at Cleveleys. The low and narrow range

4 of aggregate water absorption values meant that adjustments on added water to cater for absorptivity

5 were deemed unnecessary. Based on the trial mixing undertaken, the typical slump of the concretes used varied from 55 to $75 \mathrm{~mm}$.

\section{$7 \quad$ 2.2.2. Specimen fabrication}

8 The concrete mixtures were batched according to the respective proportions in Table 1. This was 9 followed by mixing using a rotary-drum mixer. Thereafter, the fresh concrete was placed in lubricated moulds in three approximately equal layers and each layer was compacted with a vibrating table. Any

11 excess fresh concrete was trimmed off and the top of the specimens' surfaces finished with a steel float.

12 Subsequently, test specimens were covered in a polythene sheet and stored in a room at a temperature

13 of $20 \pm 3^{\circ} \mathrm{C}$. After 24 hours, the specimens were demoulded and submerged in a water tank to cure for 14 a period of 28 days.

\subsection{Experimental procedures}

\subsubsection{Abrasion resistance}

17 The underwater (ASTM C1138) method [9] was used to evaluate the abrasion resistance of concrete specimens from a total of 21 concrete discs, three for each concrete mixture at the age of 28 days. The experimental setup used is illustrated in Figure 3. The test has been shown to qualitatively reproduce the kind of abrasion damage observed in field conditions subject to the action of water-borne sediments $[5,22,23]$. 


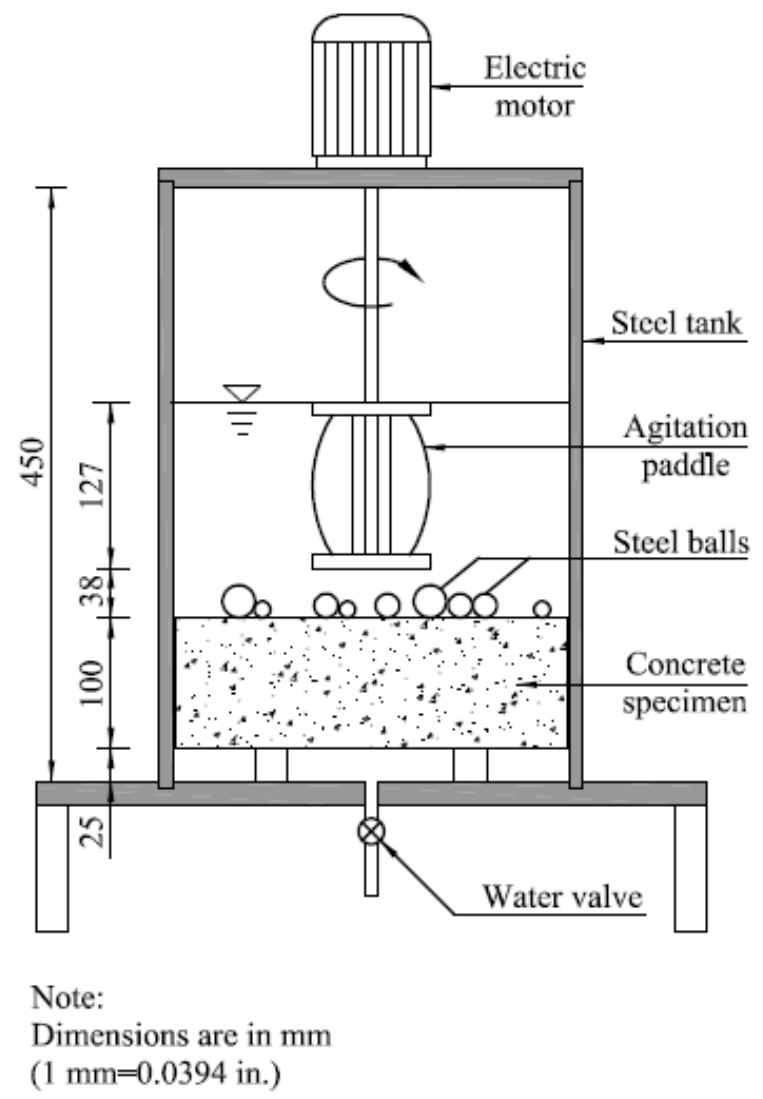

Figure 3-Experimental setup of the concrete abrasion test

3 The test entails the immersion of a concrete disc specimen in water contained in a $300 \mathrm{~mm}$ diameter 4 steel cylinder and subjecting it to the abrasive action of 70 steel chrome balls with diameters of 12.7 $5 \mathrm{~mm}$ ( $25 \mathrm{Nos}), 19.1 \mathrm{~mm}$ (35 Nos) and $25.4 \mathrm{~mm}$ (10 Nos). The steel balls are moved due to the agitation 6 of water by a paddle rotating at a speed of $1200 \mathrm{rpm}$. The volume of the abrasion-damaged concrete 7 test specimen, $V_{t}$ measured at test durations, $t$ of 24,48 and 72 hours is calculated as

$$
V_{t}=\frac{M_{a}-M_{w}}{\rho_{w}},
$$

where, $M_{a}$ and $M_{w}$ are the masses of test specimen in air and water measured to the nearest 1 gram for the selected test duration while $\rho_{\mathrm{w}}$ is the density of water assumed to be $1000 \mathrm{~kg} / \mathrm{m}^{3}$. Concrete abrasion loss $\left(\mathrm{V}_{\mathrm{abr}}\right)$ at the stated test durations is estimated as

$$
V_{a b r}=V_{0}-V_{t},
$$

in which, $V_{o}$ is the initial volume of the specimen before the test whilst $V_{t}$ is the volume at a specified time increment. Concrete abrasion loss at the 24,48 and 72 hours was expressed as a percentage of the initial specimen volume. In this study, the bottom as-struck surfaces of the concrete specimens were 
exposed to abrasion action so that the density and quality of the finish of test surfaces were comparable to those exhibited by concrete revetment armour units. Typically, these are precast units cast facedown such that the exposed surface is that originally in direct contact with the mould $[5,7,8]$. This approach produces a high-quality surface finish and ensures that a dense surface is exposed which minimises the risk of chlorides and sulphates ingress [7]. Further, the topography of the abrasiondamaged surfaces was examined from scans acquired using a 3D Sense RS scanner with an operating range of $0.35 \mathrm{~m}$ to $3.0 \mathrm{~m}$ and a spatial $\mathrm{x} / \mathrm{y}$ resolution of $0.9 \mathrm{~mm}$ at $0.5 \mathrm{~m}$ [24].

\subsubsection{Mechanical properties}

These properties were tested at the age of 28 days to monitor the concrete quality and evaluate the relations with concrete abrasion loss. The mechanical properties of concrete investigated, the respective standard test methods and sample sizes are summarised in Table 4.

\begin{tabular}{lllc}
\hline Test parameter & Test method & Specimen description & $\begin{array}{c}\text { Number of } \\
\text { samples }\end{array}$ \\
\hline Compressive strength & BS EN 12390-3 [25] & $100 \mathrm{~mm}$ cubes & 9 \\
\hline Tensile splitting strength & BS EN 12390-6 [26] & $100 \Phi \times 200 \mathrm{~mm}$ cylinders & 3 \\
\hline Modulus of elasticity & BS EN 12390-13 [27] & $100 \Phi \times 200 \mathrm{~mm}$ cylinders & 3 \\
\hline
\end{tabular}

Table 4-Experimental test programme for concrete mechanical properties

\subsubsection{Scanning Electron Microscopy}

Two concrete cube specimens of $20 \mathrm{~mm}$ sides containing a quartzite and green glass coarse particle respectively were cut out from the undamaged concrete cubes and subjected to Scanning Electron Microscopy (SEM) analysis. Electron High Tension (EHT) of $18.15 \mathrm{kV}$ was chosen to obtain lower noise on the final image, whilst the working distance was adjusted from 5.5 to $9.0 \mathrm{~mm}$ to allow shallow or depth field of view according to the area of interest.

\section{TEST RESULTS AND DISCUSSION}

\subsection{Mechanical properties}

The mean compressive strength, tensile strength and modulus of elasticity of specimens tested at the age of 28 days are summarised in Table 5 . The values of \% coefficients of variation (CV) of three test results (unless stated otherwise) are shown in the parenthesis. 


\begin{tabular}{|c|c|c|c|c|c|c|c|c|}
\hline \multirow[t]{2}{*}{ Parameter } & \multirow[t]{2}{*}{ Units } & \multicolumn{7}{|c|}{ Concrete mixtures } \\
\hline & & $\mathrm{RCO}$ & GC12.5 & GC25 & GC50 & GC100 & LCO & SC0 \\
\hline $\begin{array}{l}\text { Compressive } \\
\text { strength }\end{array}$ & $\mathrm{MPa}$ & $\begin{array}{l}45.2 \\
(8.2) \\
\end{array}$ & $\begin{array}{l}43.2 \\
(4.1) \\
\end{array}$ & $\begin{array}{l}38.0 \\
(6.0) \\
\end{array}$ & $\begin{array}{l}36.4 \\
(5.1) \\
\end{array}$ & $\begin{array}{l}33.0 \\
(3.6) \\
\end{array}$ & $\begin{array}{l}42.0 \\
(4.8) \\
\end{array}$ & $\begin{array}{l}65.7 \\
(3.6) \\
\end{array}$ \\
\hline $\begin{array}{l}\text { Tensile splitting } \\
\text { strength }\end{array}$ & IVITa & $\begin{array}{l}3.98 \\
(4.3)\end{array}$ & $\begin{array}{l}3.22 \\
(7.2)\end{array}$ & $\begin{array}{l}3.93 \\
(6.9)\end{array}$ & $\begin{array}{l}3.57 \\
(1.7)\end{array}$ & $\begin{array}{l}3.25 \\
(2.2)\end{array}$ & $\begin{array}{c}4.35 \\
(13.9)\end{array}$ & $\begin{array}{l}5.23 \dagger \\
(5.5)\end{array}$ \\
\hline $\begin{array}{l}\text { Modulus of } \\
\text { elasticity }\end{array}$ & $\mathrm{GPa}$ & $\begin{array}{l}32.8 \\
(2.8) \\
\end{array}$ & $\begin{array}{l}31.6 \\
(0.4) \\
\end{array}$ & $\begin{array}{l}32.3 \\
(4.1) \\
\end{array}$ & $\begin{array}{l}35.8 \\
(1.6)\end{array}$ & $\begin{array}{l}33.7 \\
(4.4) \\
\end{array}$ & $\begin{array}{l}34.7 \\
(5.6) \\
\end{array}$ & $\begin{array}{c}39.3 \\
(10.2) \\
\end{array}$ \\
\hline
\end{tabular}

\section{Table 5-Mechanical properties of the concrete mixtures used}

\subsubsection{Compressive strength}

The results in Table 5 show that in comparison to the control mixture (RC0), glass-aggregate concretes (GC12.5 to GC100) exhibited relatively low compressive strengths. The use of $12.5 \%, 25 \%, 50 \%$ and $100 \%$ recycled waste coarse aggregates as replacement for bunter quartzite reduced the mean compressive strength by $4 \%, 16 \%, 20 \%$ and $27 \%$ respectively. Further, the mean compressive strength of mixture GC100 was $21 \%$ lower than that of LCO while all mixtures in the GC series were $34 \%$ to $50 \%$ lower than the field concrete mixture (SCO) in terms of compressive strength.

The trend of reduced compressive strength with increased glass coarse aggregate content is generally consistent with many published past studies [11-13, 18]. Test results obtained by Topçu and Canbaz [11] showed that use of $15 \%, 30 \%, 45 \%$ and $60 \%$ reduced the compressive strength of glass-aggregate concretes by $8 \%, 15 \%, 31 \%$, and $49 \%$ respectively. Similarly, Serpa et al. [13] showed that use of $5 \%$, $10 \%$ and $20 \%$ glass coarse aggregates reduced compressive strength by $7 \%, 9 \%$ and $10 \%$ respectively. The same study also found that combined use of glass coarse and fine aggregates was more detrimental to compressive strength due to $14 \%, 17 \%$ and $27 \%$ reductions. Tests results by Terro [12] at a temperature of $20^{\circ} \mathrm{C}$ also showed that use of $25 \%, 50 \%$ and $100 \%$ glass coarse aggregates reduced compressive strength by $1 \%, 17 \%$ and $23 \%$ respectively whilst an improvement of $9 \%$ was recorded at glass coarse aggregate content of $10 \%$. Terro's [12] compressive strength results for combined use coarse and fine glass aggregates were worse than the use of glass coarse aggregates only as evidenced by $8 \%, 34 \%, 62 \%$ and $68 \%$ decrements in compressive strength. It appears it is only Sangha et al [14] who report marginal compressive strength enhancements of up to $8 \%$ at 28 days for concretes produced with coarse and fine glass aggregates in dosages of up to $60 \%$. But even in this investigation, there was $2 \%$ reduction in compressive strength at a glass-aggregate content of $20 \%$. 


\subsubsection{Tensile splitting strength}

The results in Table 5 show that the addition of glass coarse aggregates generally reduced the tensile splitting strength of concrete. It is shown that use of glass coarse aggregate contents of $12.5 \%, 25 \%$, $50 \%$ and $100 \%$ resulted in $19 \%, 1 \%, 10 \%$ and $18 \%$ reduction in mean tensile strength respectively. However, there is some inconsistency in the pattern caused by the results of the mixture GC12.5 which exhibited markedly low mean tensile splitting strength than both RC0 and GC25. The reasons for the unexpected low value are not apparent, and as such is considered an outlier probably due to an undetected flaw in either the test specimens or setup used. The concrete mixture with $100 \%$ glass coarse aggregates also had the mean tensile splitting strength that was $25 \%$ lower than that of the limestone-aggregate mixture. When compared with the field concrete (SC0) mixtures GC12.5, GC25, GC50 and GC100 displayed mean tensile splitting strengths that were lower by $38 \%, 25 \%, 32 \%$ and $38 \%$ respectively.

The observed effect of glass coarse aggregate use on tensile splitting strength is in agreement with the results of previous studies. Topçu and Canbaz [11] reported that use of glass coarse aggregates in dosages of $15 \%, 30 \%, 45 \%$ and $60 \%$ reduced the concrete tensile splitting strength by $10 \%, 11 \%, 9 \%$ and $37 \%$ respectively. A similar trend was also found by Serpa et al. [13] who showed that use of $5 \%$, $10 \%$ and $20 \%$ glass coarse aggregates resulted in tensile splitting strength decrease by $17 \%, 17 \%$ and $29 \%$ respectively. At the same waste glass contents but using a combination of coarse and fine glass aggregates, Serpa et al. [13] again found respective tensile splitting strength reductions of $21 \%, 21 \%$ and $31 \%$. It would appear that decreased tensile splitting strength should be expected in concretes incorporating recycled waste glass coarse aggregates at the age of 28 days. However, results by Sangha et al. [14] suggest that glass-aggregate (40\%) concretes tended to gain over $50 \%$ of the 28 day tensile splitting strength after 2 years.

The reduction in compressive and tensile splitting strengths can be attributed to the poor (flaky) shape of glass coarse aggregates which results in a mix lacking homogeneity in aggregate distribution [18]. The flat-nature of the glass coarse aggregates implies that they tend to be oriented to a common plane and can collect bleed water which weakens the glass-cement paste bond. The weak bonds between the concrete phases are further exacerbated by the smooth surfaces of glass coarse aggregates [18]. This suggests that on application of stress, cracks are initiated in the interfacial transition zone (ITZ). The crack propagation causes the glass coarse aggregates to detach from the paste thus leading to 
glass-aggregate concretes failing at loads relatively inferior to those of the control mix. An inspection of the samples after testing revealed that the failure mode was primarily by cracking at the glass aggregate-matrix interface rather than glass-aggregate fracture. The failure patterns observed in this study contradict the suggestion by Topçu and Canbaz [11] that the reduced compressive strength of glass-aggregate concretes was due to the high brittleness of glass aggregates. The strength of the ITZ is also still subject to dispute in literature as Sangha et al. [14] suggested that the modest compressive strength enhancements were due to the glass-paste bond being stronger than the flint natural aggregate used. Therefore, while there is some consistency that use of glass coarse aggregates reduces both compressive and tensile splitting strengths, the behaviour of the ITZ requires thorough investigations.

\subsubsection{Modulus of elasticity}

The results in Table 5 show that the use of glass coarse aggregates did not have a systematic effect on its modulus of elasticity based on the mean values. The use of glass coarse aggregates in contents of up to $25 \%$ resulted in small reductions in the modulus of elasticity of up to $2 \%$ whilst $50 \%$ and $100 \%$ glass coarse aggregate contents resulted in $9 \%$ and $3 \%$ increments in the modulus of elasticity respectively. This behaviour is consistent with the results of Serpa et al. [13] who also found that addition of $5 \%$ and $20 \%$ glass coarse aggregates in concrete increased its modulus of elasticity by $5 \%$ and $3 \%$ respectively, the use of $10 \%$ caused a reduction of just $1 \%$. However, the combined use of fine and coarse glass aggregates generally reduced the concrete modulus of elasticity by $3 \%$ to $5 \%$ for glass contents of $5 \%$ to $20 \%$ [13]. On the other hand, the modulus of elasticity of the concrete mixture with $100 \%$ glass coarse aggregates was $3 \%$ lower than for the limestone-aggregate mixture. When compared with high-strength concrete typically used in abrasive conditions (SCO), the GC series mixtures exhibited decrements in modulus of elasticity that varied from $9 \%$ to $20 \%$.

\subsection{Concrete abrasion resistance}

Testing for hydrodynamic abrasion resistance of glass and natural-aggregate concretes at the age of 28 days was undertaken using the ASTM C1138 method. Figure 3 (A-C) shows some of the concrete test specimens after 72 hours of abrasion action whilst the abrasion losses measured at test durations of 24, 48 and 72 hours are presented in Figure 4. 


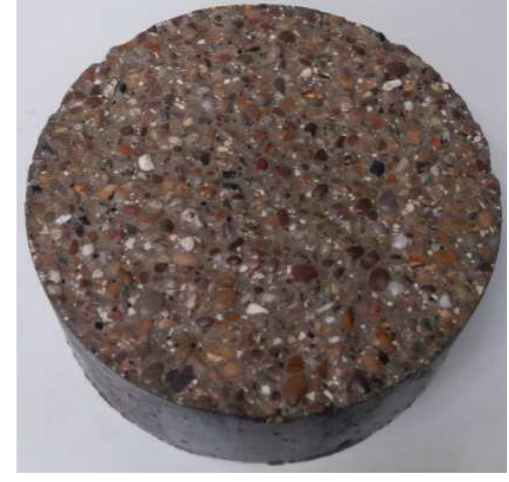

(A)-Mixture RC0

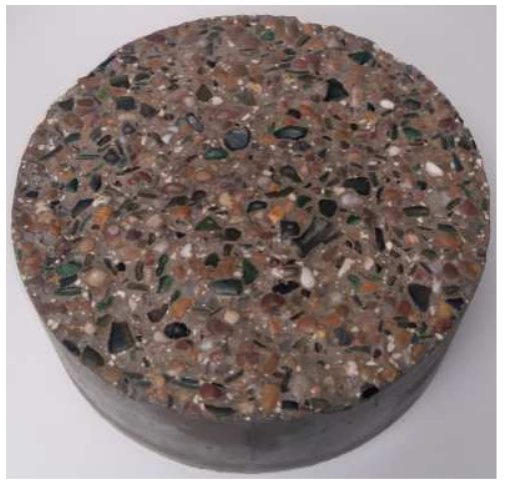

(B)-Mixture GC25

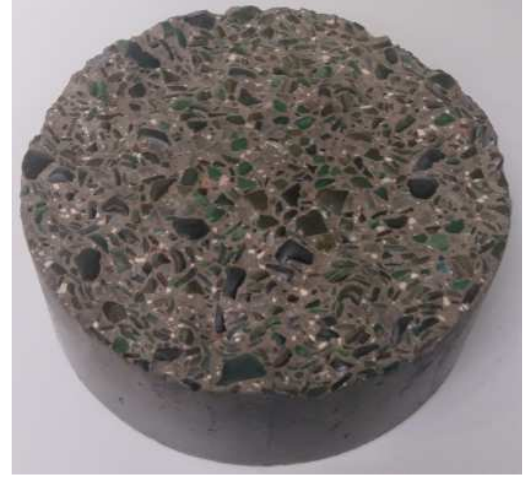

(C) - Mixture GC100

Figure 3-Test specimens abraded for 72 hours in the ASTM C1138 test

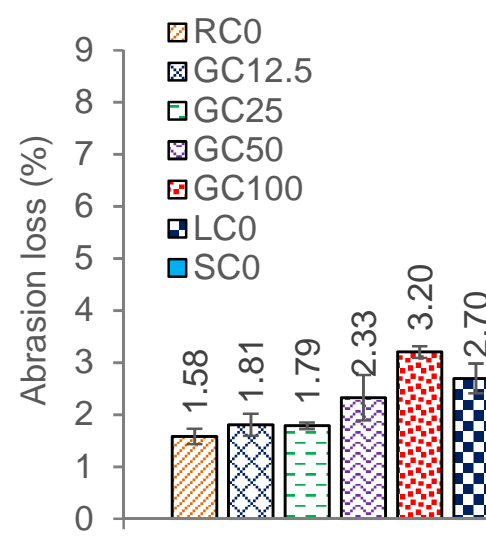

24
2

4

5

6

7

8

9
西

4

confidence. The confidence level selected is consistent with that typically used to determine the characteristic properties of structural materials [28]. Based on the sample size of three for each concrete mixture, it was not possible to ascertain if the samples were drawn from a normally distributed population, nonparametric analysis of variance (ANOVA) test was used to assess the differences between the sample groups. The abrasion resistance of glass aggregate concretes was compared to both reference and high-strength field mixtures using the Kruskal-Wallis test [29]. 
1 The Kruskal-Wallis test is a nonparametric ANOVA by ranks test. It is performed by first pooling and

2 then ranking the data from each sample. This is followed by the computation of the sum ranks of each sample and calculation of the Kruskal-Wallis $\mathrm{H}$ statistic. The distribution of the $\mathrm{H}$ is approximately ChiSquare $\left(\chi^{2}\right)$ with the degrees of freedom (DF) equal to the number of sample groups compared minus one [29]. The $p$-value is then computed and compared with the significance level $(\alpha=0.05)$ to make a decision [29]. This statistical test method has been successfully used for statistical significance tests in past concrete studies [30, 31].

\subsubsection{Effect of recycled waste glass aggregate content}

The influence of the amount of glass coarse aggregate on concrete abrasion resistance was investigated by comparing the abrasion losses in the GC mixture series with that of the control concrete (RC0). These results are summarised in Table 6.

\begin{tabular}{|c|c|c|c|c|c|c|}
\hline \multirow{3}{*}{$\begin{array}{l}\text { Concrete } \\
\text { mixture }\end{array}$} & \multicolumn{6}{|c|}{ Abrasion results } \\
\hline & \multicolumn{2}{|c|}{24 hours } & \multicolumn{2}{|c|}{48 hours } & \multicolumn{2}{|c|}{72 hours } \\
\hline & $\Delta(\%)$ & CV (\%) & $\Delta(\%)$ & CV (\%) & $\Delta(\%)$ & CV (\%) \\
\hline RCO & - & 9 & - & 9 & - & 13 \\
\hline GC12.5 & -14 & 12 & -20 & 14 & -22 & 18 \\
\hline GC25 & -13 & 14 & -8 & 10 & -4 & 12 \\
\hline GC50 & -47 & 19 & -53 & 10 & -44 & 7 \\
\hline GC100 & -102 & 3 & -172 & 3 & -219 & 1 \\
\hline
\end{tabular}

Table 6-Effect of glass aggregate content on abrasion resistance

Table 6 shows that the use of recycled waste glass to either partially or fully replace natural coarse aggregates in concrete generally reduced its abrasion resistance. Based on the changes in abrasion resistance obtained and considering the coefficients of variation $(\mathrm{CV})$ of the test data, the use of glass coarse aggregates in contents of up to $25 \%$ of the total coarse aggregate did not have a profound effect on abrasion resistance. However, at higher glass coarse aggregate contents of $50 \%$ and $100 \%$, its deleterious effect on concrete abrasion performance became prominent. As shown in Table 7, the Kruskal-Wallis test confirmed that glass aggregate use in contents of up to $25 \%$ did not have a statistically significant effect on concrete abrasion resistance at all the evaluated test durations.

\begin{tabular}{|l|c|c|c|c|c|c|c|c|c|}
\hline \multirow{2}{*}{$\begin{array}{l}\text { Concrete } \\
\text { mixture }\end{array}$} & \multicolumn{9}{|c|}{ Abrasion results } \\
\cline { 2 - 9 } & $\chi^{2}$ & DF & p-value & $\chi^{2}$ & DF & p-value & $\chi^{2}$ & DF & p-value \\
\hline RC0 & \multirow{2}{*}{3.467} & 2 & 0.177 & 2.756 & 2 & 0.252 & 3.467 & 2 & 0.177 \\
\hline GC12.5 & & & & & & & & & \\
\hline GC25 & & & & &
\end{tabular}

\section{Table 7-Kruskal-Wallis test for the control mixture versus glass aggregate concretes}


1 As mentioned in the previous section, Serpa et al. [13] used the Böhme [20] method and reported that

2 the use of glass coarse aggregates in contents of $5 \%, 10 \%$ and $20 \%$ enhanced abrasion resistance by $39 \%, 11 \%$ and $16 \%$ respectively. Similarly, the introduction of coarse and fine glass aggregates at the

4 5 same contents resulted in relatively mild abrasion resistance improvements of $0.7 \%, 2.8 \%$ and $5.6 \%$ respectively [13]. Although concrete material removal mechanisms in the Böhme [20] and ASTM C1138 [9] methods are radically different, findings of Serpa et al [13] suggest that use of glass coarse aggregates in moderate quantities is not detrimental to abrasion performance which is in agreement with the results of the present study. The insignificant effect of glass coarse aggregate use in moderate contents of up to $25 \%$ on concrete abrasion resistance can be attributed to fact that the Mohs Hardness index of glass coarse aggregates of $\approx 5.5$ is relatively close to that of quartzite of $\approx 7.0$. As such, when the amount of glass coarse aggregate is increased, the effect of its poor shape becomes pronounced which consequently lowers the degree packing in the concrete, consequently reducing resistance. The visual examination of the abraded materials at the base of the test rig revealed that for concretes with glass contents of $50 \%$ and $100 \%$, there was a considerable degree of plucking of glass aggregate particles when compared to the reference mixture which did not exhibit obvious plucking of the natural coarse aggregates. This indicates that the coarse glass particles were more vulnerable to removal due a weaker interface between the glass aggregates and matrix as a result of their inherent smooth surface texture. This contradicts the results of the study by Sangha et al. [14] in which modest strength improvements were attributed to a stronger interface between cement paste and glass aggregates compared to the flint aggregate based on images obtained by optical microscopy. Figures 5 and 6 present the SEM images of the glass-matrix-quartzite and cement paste-green glass aggregate interfaces respectively for the present study. Figure 5 was obtained using the back scattered electrons detector to analyse the surface based on the atomic number of the sample and differentiate its components whilst Figure 6 used the scattered electron detector to analyse the sample based on its morphology. 


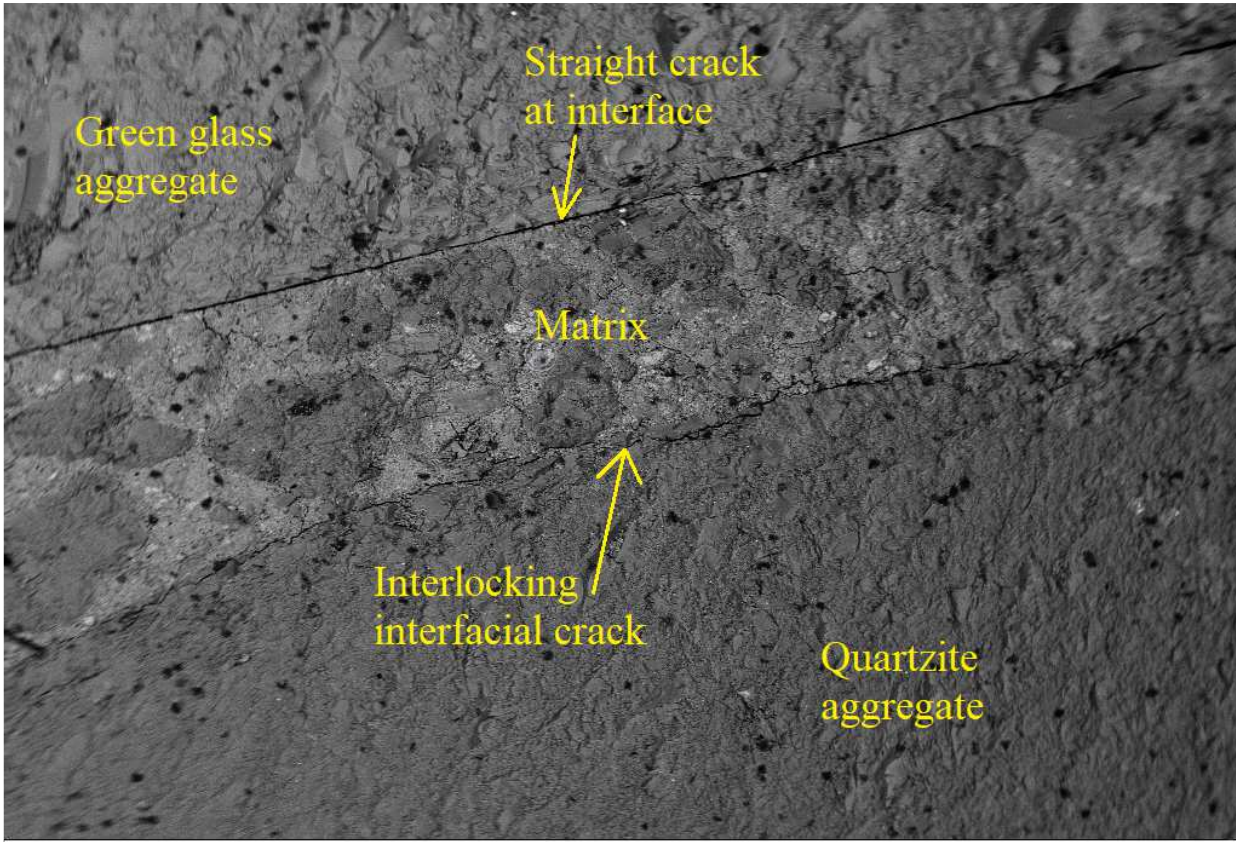

$200 \mu m$

Figure 5-Glass-matrix-quartzite aggregate interface

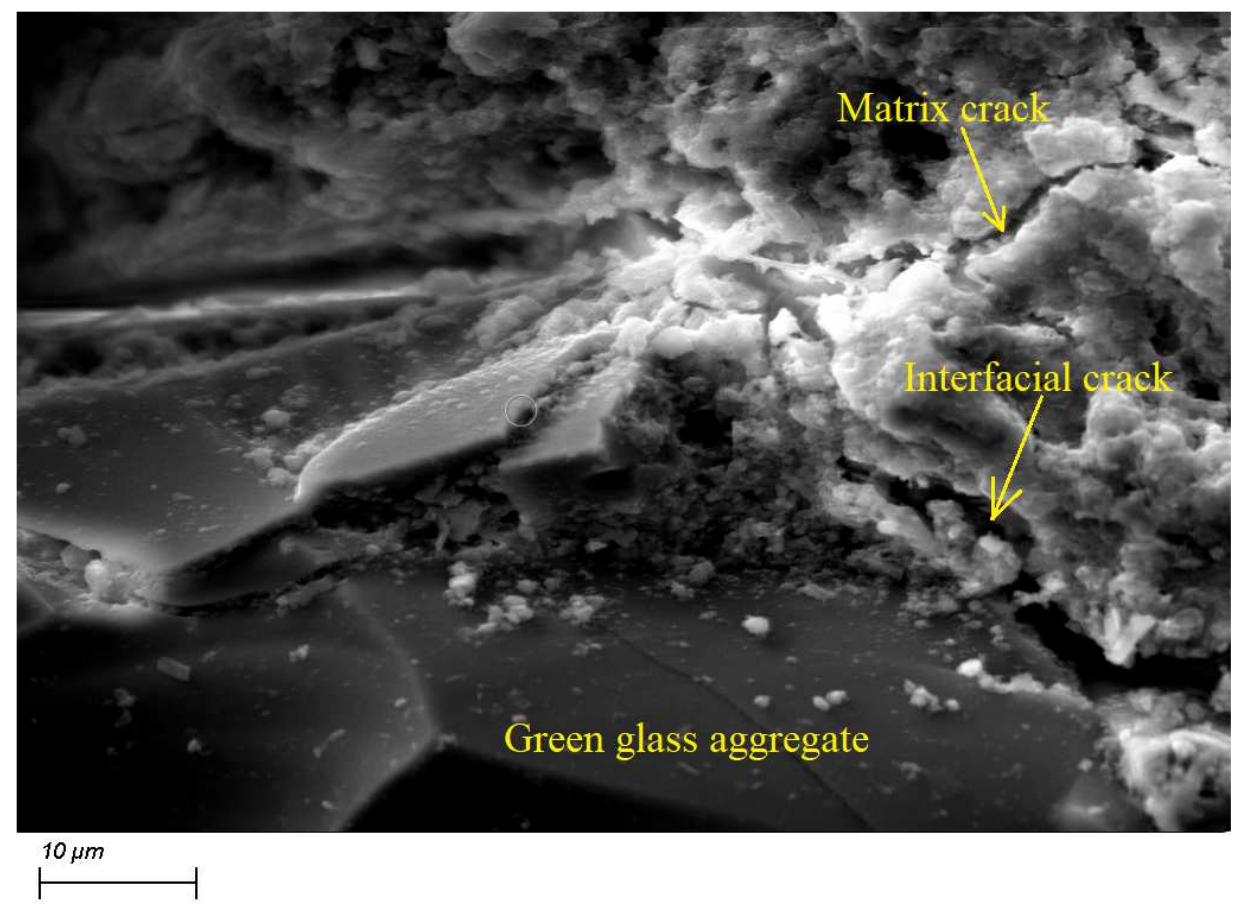

Figure 6-Glass aggregate-cement paste interface

5 Figures 5 and 6 show that there was micro-cracking at the interface of the matrix and coarse aggregate

6 for both quartzite and green glass. However, contrary to Sangha et al. [14], there was evidence of a

7 better interlock between the matrix and quartzite particle when compared to glass which indicates a

8 higher bond strength in the latter and possibly explains the reduced abrasion resistance of glass- 
aggregate concrete mixtures. It can therefore be summed up that the good abrasion resistance offered by glass-aggregate concretes at low glass dosages is due to the high Mohs hardness index of glass, but at high glass contents, the mixture becomes segregated due to the increased influence of the poor shape of the glass aggregate particles and a relatively weak interfacial bond between glass aggregate and cement paste resulting in decreased abrasion resistance.

After demonstrating the possibility of incorporating waste glass as coarse aggregates for concrete in abrasive hydrodynamic conditions, it is useful to establish relations to predict the abrasion loss in glassaggregate concretes from the glass aggregate content. Figure 7 shows the variation of concrete abrasion loss and the glass coarse aggregate quantity at test durations of 24,48 and 72 hours.

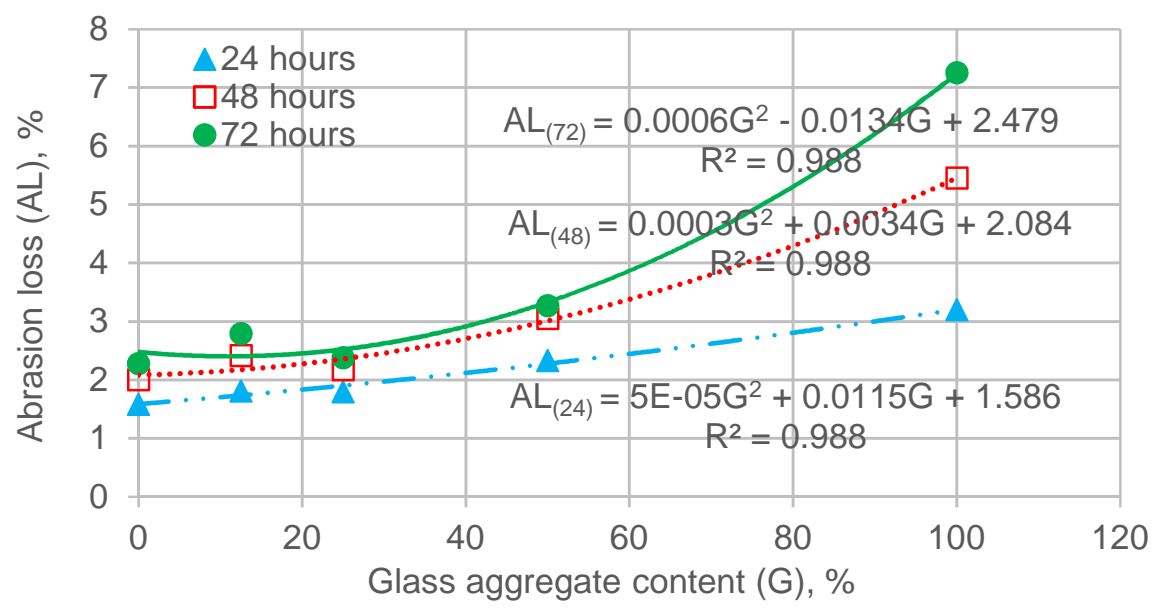

Figure 7-Relation between abrasion loss and glass CA content

Regression analysis was used to compare the different forms of the relations based on the values of the coefficient of determination $\left(R^{2}\right)$ at each test duration. The test data was generally found to excellently fit a polynomial function of second order $\left(R^{2}=0.99\right)$ at all the three test durations. It was also found that at $95 \%$ confidence, glass coarse aggregate content explained a significant proportion of variance in concrete abrasion loss $(p<0.05)$ at 24,48 and 72 hour test durations as shown in Table 8.

\begin{tabular}{|c|c|c|}
\hline $\begin{array}{c}\text { Test duration } \\
\text { (hours) }\end{array}$ & $\begin{array}{c}\text { F-statistic } \\
\left(\mathrm{DF}_{1}, \mathrm{DF}_{2}\right)\end{array}$ & p-value \\
\hline 24 & $81.04(2,2)$ & \multirow{2}{*}{0.012} \\
\hline 48 & $79.57(2,2)$ & \\
\hline 72 & $80.81(2,2)$ & \\
\hline \multicolumn{2}{|c|}{$\mathrm{DF}_{1}$ and $\mathrm{DF}_{2}$ denote degrees of freedom for the } \\
regression model and residuals respectively
\end{tabular}

Table 8-F-test on the significance of the relation between concrete abrasion loss and glass aggregate content 
1 The significant relations obtained indicate that for the concrete mixtures tested, the empirical relations

2 shown in Figure 7 can be used to predict the abrasion loss in the ASTM C1138 test for concretes containing recycled waste glass as coarse aggregates at 24,48 and 72 hours.

\subsubsection{Glass-aggregate concretes versus the field mixture}

5

The comparison of the abrasion resistance of glass-aggregate concretes with that of the high-strength concrete typically used in field applications (SC0) is presented in Table 8.

\begin{tabular}{|l|c|c|c|c|c|c|}
\hline \multirow{3}{*}{ Mixture } & \multicolumn{7}{|c|}{ Abrasion resistance } \\
\cline { 2 - 7 } & \multicolumn{2}{|c|}{24 hours } & \multicolumn{2}{c|}{48 hours } & \multicolumn{2}{c|}{72 hours } \\
\cline { 2 - 7 } & $\Delta(\%)$ & $\mathrm{CV}(\%)$ & $\Delta(\%)$ & $\mathrm{CV}(\%)$ & $\Delta(\%)$ & $\mathrm{CV}(\%)$ \\
\hline SC0 & - & 15 & - & 2 & - & 7 \\
\hline GC12.5 & -28 & 12 & -25 & 14 & -12 & 18 \\
\hline GC25 & -27 & 14 & -13 & 10 & +4 & 12 \\
\hline GC50 & -65 & 19 & -59 & 10 & -32 & 7 \\
\hline GC100 & -127 & 3 & -184 & 3 & -192 & 1 \\
\hline
\end{tabular}

Table 9-Glass-aggregate concretes versus a practical high-strength concrete mixture

It is observed in Table 9 that the high-strength concrete mixture generally outperformed all the glassaggregates concretes at all the three test durations evaluated with the exception of mixture GC25 at 72 hours. At this test period, the abrasion resistance of GC25 was slightly higher than that of the site concrete mixture by $4 \%$. However, only small differences in performance were found at glass coarse aggregate contents of up to $25 \%$ (GC12.5 and GC25) while concrete mixtures with $50 \%$ and $100 \%$ glass coarse aggregate replacements (GC50 and GC100) exhibited run-away abrasion losses. To further investigate the differences shown in Table 9 between the abrasion resistance of concretes with up to $25 \%$ glass coarse aggregates and that used in an abrasive field site, while taking into account the noise in the data, the statistical significance test was performed. The results of the Kruskal-Wallis test at $95 \%$ confidence are presented in Table 10.

\begin{tabular}{|c|c|c|c|c|c|c|c|c|c|}
\hline \multirow{3}{*}{$\begin{array}{l}\text { Concrete } \\
\text { mixture }\end{array}$} & \multicolumn{9}{|c|}{ Abrasion results } \\
\hline & \multicolumn{3}{|c|}{24 hours } & \multicolumn{3}{|c|}{48 hours } & \multicolumn{3}{|c|}{72 hours } \\
\hline & $\chi^{2}$ & DF & $p$-value & $\chi^{2}$ & $\mathrm{DF}$ & $p$-value & $\chi^{2}$ & $\mathrm{DF}$ & $p$-value \\
\hline $\mathrm{RCO}$ & \multirow{3}{*}{4.36} & \multirow{3}{*}{2} & \multirow{3}{*}{0.113} & \multirow{3}{*}{4.62} & \multirow{3}{*}{2} & \multirow{3}{*}{0.099} & \multirow{3}{*}{2.76} & \multirow{3}{*}{2} & \multirow{3}{*}{0.252} \\
\hline GC12.5 & & & & & & & & & \\
\hline GC25 & & & & & & & & & \\
\hline
\end{tabular}

\section{Table 10-Kruskal-Wallis test for glass aggregate concretes versus site mixture}

Table 10 demonstrate that at a significance level of 0.05 , abrasion in concrete mixtures with up $25 \%$ glass coarse aggregates were not significantly different from that of site mixture $(p>0.05)$ at test durations of 24,48 , and 72 hours. 
1 These results indicate that in terms of abrasion resistance, glass-aggregate concretes can offer 2 performance that is comparable to that of high-strength mixtures used in abrasive field conditions. 3 However, it should be noted that besides using hard crushed andesite hornfels as coarse aggregates, 4 mixture SC0 also contained silica fume. Evidence from previous studies on natural-aggregate concretes $5[32,33]$ confirms that silica fume use in doses of around $10 \%$ of the cement content enhances its abrasion resistance. Kumar and Sharma [32] reported abrasion resistance increments of up to $40 \%$ due to addition of silica fume at a dose of $10 \%$ of the cement content. Kang et al. [33] also found $86 \%$ improvement in abrasion resistance when silica fume at a dose of $7 \%$ of the cement content was added

9 to the mixture.

It is thus postulated that the moderate reductions in the performance of mixtures GC12.5 and GC25 could be offset by the addition of an appropriate amount of silica fume. This could produce glassaggregate concretes with abrasion resistance comparable to that of mixture SCO which would enable utilisation of waste glass to produce high-performance concretes for use in abrasive exposure conditions. However, this hypothesis needs to be confirmed with further experimental investigations. Figures 8 and 9 for concretes SC0 and GC100.

17

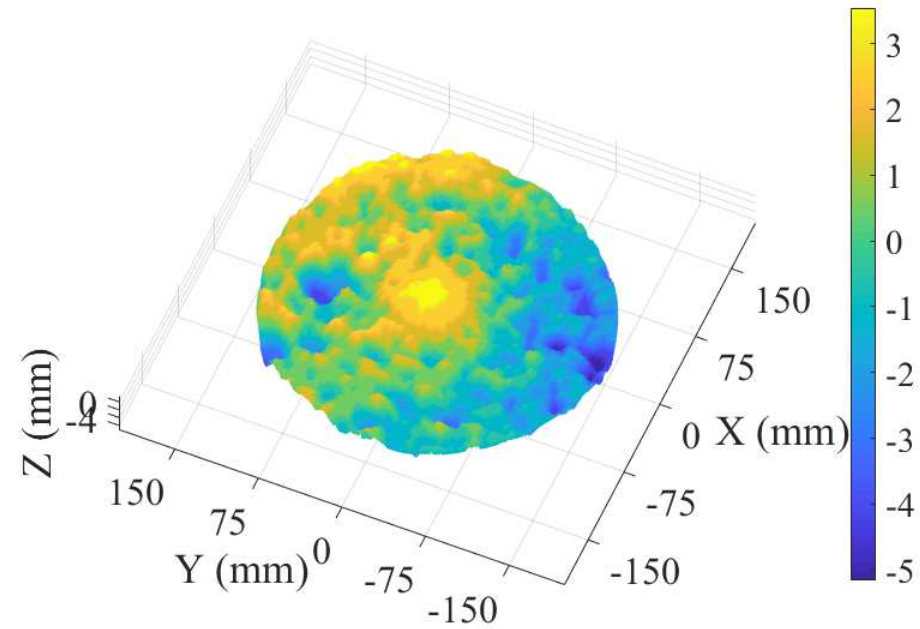




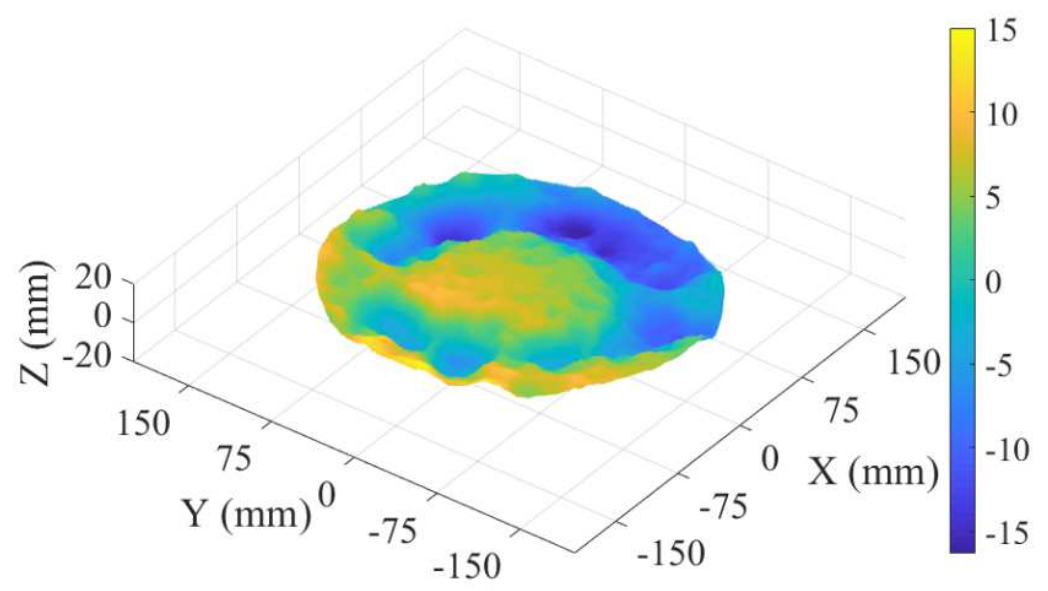

1

Figure 9-Abrasion-damaged surface of concrete GC100 at 72 hours

3 The minimum and maximum surface excursions from the mean level for mixture SC0 were -5.16 and $4+3.54 \mathrm{~mm}$ respectively, and -16.30 and $15.10 \mathrm{~mm}$ respectively for mixture GC100. The influence of coarse aggregate hardness on the characteristics of the abraded surface of mixture SCO shown in

6 Figure 8 is evidenced by the coarse aggregates and cement/sand comprising the crests and troughs respectively. In contrast, Figure 9, shows that the abrasion rates of the glass coarse aggregates and the matrix were comparable which resulted in large depressions with gradual transitions from the crests to the troughs of the abraded surfaces. In the experiment, the abraded glass particles were smooth to touch thus indicating that the abrasion-damaged surfaces are unlikely to pose any laceration risks when used in areas accessible to the public in the case of coastal defences. In summary, it is evident that incorporation of recycled waste glass as coarse aggregates in proportions of up to $25 \%$ produces concretes that perform well when compared to the high-strength mixtures typically specified for abrasive coastal conditions. The degree of abrasion resistance exhibited, coupled with the possibility of adding silica fume to enhance it, as well as the satisfactory quality of abraded glass-aggregate concrete surfaces indicates that recycled waste glass is a promising environmentfriendly alternative for use as coarse aggregates in concrete hydraulic structures. Indeed, the use of up to $25 \%$ glass as coarse aggregates in concrete-intensive structures such as coastal defences and hydroelectric dams would provide a sustainable destination for the considerable amount of waste glass generated globally. 


\subsubsection{Limestone and recycled waste glass aggregates}

Limestone with Los Angeles (LA) abrasion loss of less than $30 \%$ can be used in abrasive conditions [6]. The possible use of waste glass to replace softer natural aggregates such as limestone was assessed based on Figure 4 by comparing the performance of mixtures GC100 and LC0 in Table 11.

\begin{tabular}{|l|c|c|c|c|c|c|}
\hline \multirow{2}{*}{$\begin{array}{l}\text { Concrete } \\
\text { mixture }\end{array}$} & \multicolumn{7}{|c|}{ Abrasion resistance } \\
\cline { 2 - 7 } & \multicolumn{2}{|c|}{24 hours } & \multicolumn{2}{|c|}{48 hours } & \multicolumn{2}{c|}{72 hours } \\
\cline { 2 - 7 } & $\Delta(\%)$ & $\mathrm{CV}(\%)$ & $\Delta(\%)$ & $\mathrm{CV}(\%)$ & $\Delta(\%)$ & $\mathrm{CV}(\%)$ \\
\hline LC0 & - & 11 & - & 8 & - & 3 \\
\hline GC100 & -19 & 3 & -4 & 3 & +2 & 1 \\
\hline
\end{tabular}

Table 11-100\% glass-aggregate versus a limestone-aggregate concrete mixture

Table 11 shows that at 24 hours, mixture LC0 out-performed GC100, but at 48 and 72 hours, the abrasion resistance of the two concretes was comparable. These results show that in terms of abrasion resistance, glass-aggregate concretes can offer similar performance to limestone concretes.

It should be recalled that the Mohs hardness values of glass and limestone coarse aggregates were about 5.5 and 3.5 respectively. Based on Liu's [22] conclusion on the influence of Mohs hardness values of coarse aggregates on concrete abrasion resistance, mixture GC100 would have been expected to display better resistance owing to the better hardness of glass aggregates. However, it appears that the enhanced abrasion resistance expected from the glass hardness was completely suppressed by the deleterious effects of their poor particle shape and smooth surface texture. Therefore, it can be concluded that in spite of suffering reduced compressive and tensile strengths, glass coarse aggregates appear to be a plausible aggregate alternative to softer rocks such as limestone in terms of abrasion performance. The comparable abrasion resistance of mixtures GC100 and LC0 obtained at 48 and 72 hours together with the environmental benefits utilising waste makes glass-aggregate a more attractive option than limestone, particularly in areas where moderate abrasion is expected.

\subsection{Relation between abrasion loss and basic mechanical properties}

The use of the basic mechanical properties of concrete, i.e. compressive strength, tensile splitting strength and modulus of elasticity to predict abrasion loss was investigated by examining their relations using regression analysis as shown in Figures $\mathbf{1 0}$ to $\mathbf{1 2}$. The tensile strength result of mixture GC25 was omitted in this analysis as it was deemed to be an outlier. The various forms of relations were first compared based on the values of the coefficient of determination $\left(R^{2}\right)$. A second-order polynomial function was found to be the best fit for the test data. Other researchers [34-36] have also used second- 
order polynomials to model the relation between abrasion loss and compressive strength, and since compressive strength is correlated with both tensile splitting strength $[37,38]$ and modulus of elasticity $[39,40]$, it was no surprise that abrasion loss could also be related to tensile strength and modulus of elasticity using a second-order polynomial function. As presented in Figures 10 to 12 , for the three test durations considered, compressive strength, tensile splitting strength and modulus of elasticity explained 93.3 to $94.4 \%, 99.2$ to $99.8 \%$ and 37.8 to $41.1 \%$ of the variation in concrete abrasion loss respectively.

The excellent correlation between abrasion loss and tensile splitting strength is consistent with the evaluation of test results by Horszczaruk [41] on conventional concretes with 28-day cube compressive strength values that varied from 47.8 to $61.6 \mathrm{MPa}$ which also showed that tensile strength exhibited higher $\mathrm{R}^{2}$ values than compressive strength when correlated with abrasion loss. The results of significance tests on compressive strength, tensile splitting strength and modulus of elasticity as independent variables for prediction of concrete abrasion loss in the ASTM C1138 method using the Ftest are presented in Table 12.

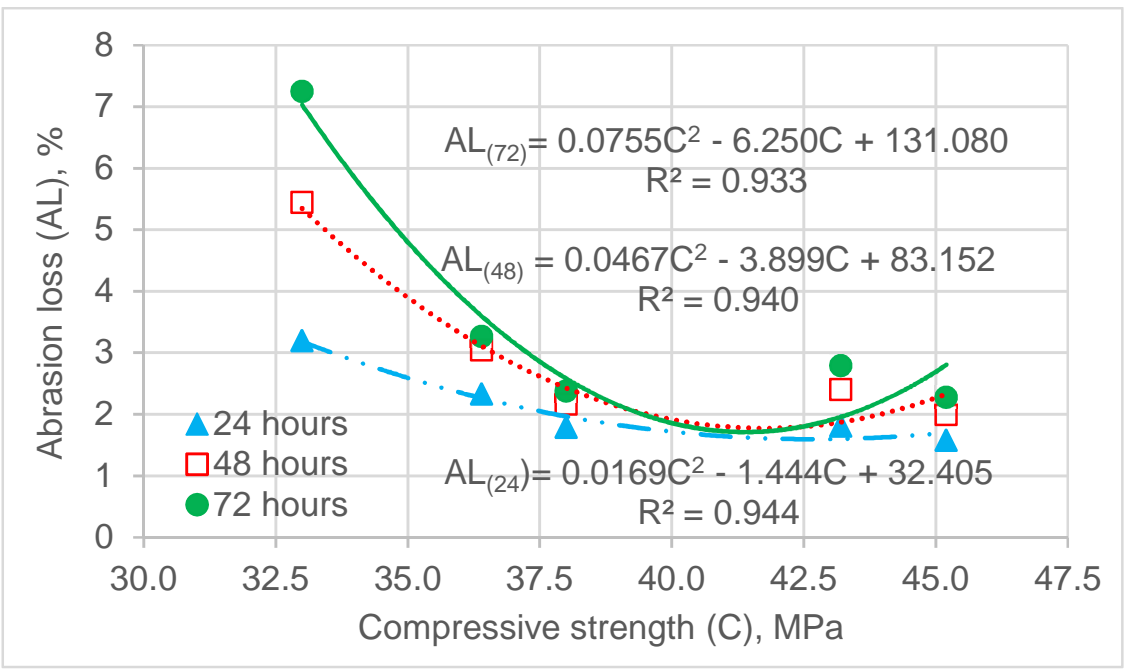




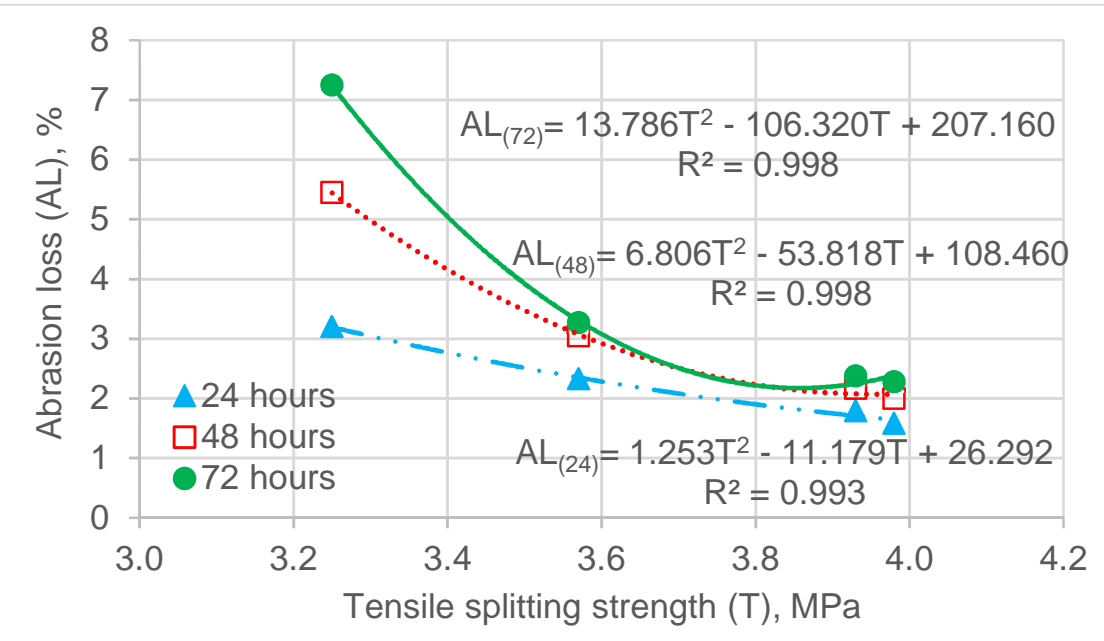

Figure 11-Concrete abrasion loss versus tensile splitting strength

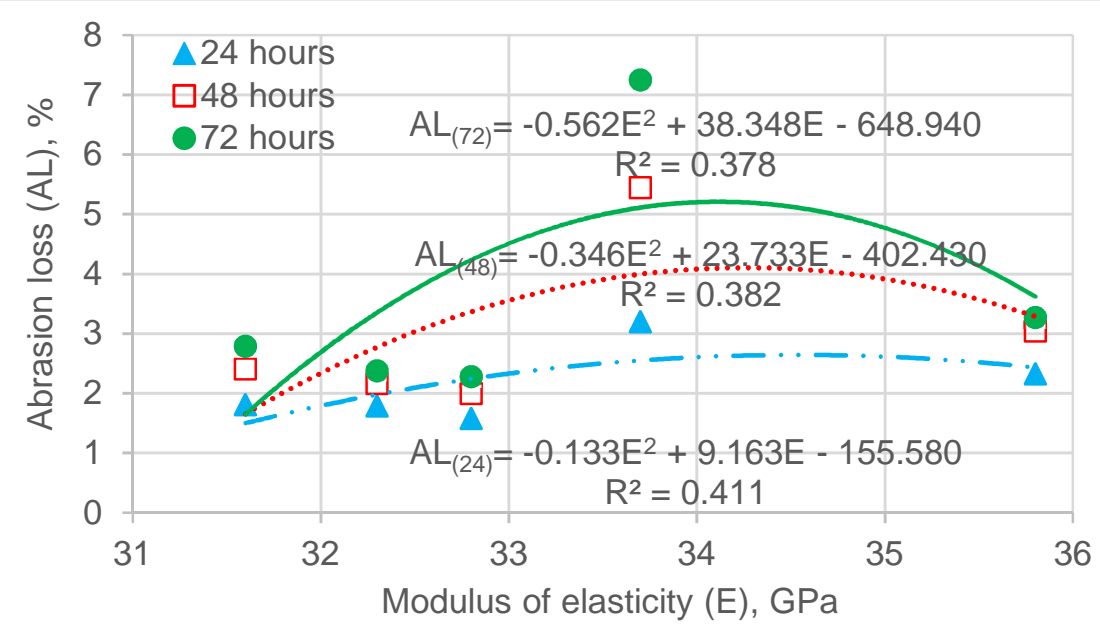

Figure 12-Concrete abrasion loss versus modulus of elasticity

\begin{tabular}{|c|c|c|c|c|c|c|}
\hline \multirow{2}{*}{$\begin{array}{l}\text { Test } \\
\text { duration } \\
\text { (hours) }\end{array}$} & \multicolumn{2}{|c|}{ Compressive strength } & \multicolumn{2}{|c|}{ Tensile splitting strength } & \multicolumn{2}{c|}{ Modulus of elasticity } \\
\cline { 2 - 7 } & $\begin{array}{l}\mathrm{F} \text {-statistic } \\
\left(\mathrm{DF}_{1}, \mathrm{DF}_{2}\right)\end{array}$ & p-value & $\begin{array}{l}\text { F-statistic } \\
\left(\mathrm{DF}_{1}, \mathrm{DF}_{2}\right)\end{array}$ & p-value & $\begin{array}{c}\text { F-statistic } \\
\left(\mathrm{DF}_{1}, \mathrm{DF} \mathrm{F}_{2}\right)\end{array}$ & p-value \\
\hline 24 & $16.93(2,2)$ & 0.056 & $68.67(2,1)$ & 0.085 & $0.70(2,2)$ & 0.589 \\
\hline 48 & $15.76(2,2)$ & 0.060 & $245.83(2,1)$ & 0.045 & $0.62(2,2)$ & 0.618 \\
\hline 72 & $13.90(2,2)$ & 0.067 & $280.05(2,1)$ & 0.042 & $0.61(2,2)$ & 0.622 \\
\hline
\end{tabular}

$\mathrm{DF}_{1}$ and $\mathrm{DF}_{2}$ denote degrees of freedom for the regression model and residuals respectively

Table 12-Comparison of compressive strength, tensile splitting strength and modulus of elasticity as model variables

The results in Table 12 show that at 95\% confidence, the variation in concrete abrasion loss was significantly influenced by tensile splitting strength $(p<0.05)$ at 48 and 72 hours. In contrast, the relations with compressive strength and modulus of elasticity were not statistically significant $(p>0.05)$ as determined by the results of the F-test. Based on the limited scope of the concrete mixtures and number of samples investigated, these results indicate that tensile splitting strength is more suitable for use as 
1 a parameter for prediction of the abrasion resistance of concretes incorporating glass coarse

2 aggregates when compared to compressive strength and modulus of elasticity.

\section{4. SUMMARY, CONCLUSIONS AND RECOMMENDATIONS}

4 This study used the ASTM C1138 method to investigate the hydrodynamic abrasion resistance of concrete mixtures incorporating recycled waste glass as coarse aggregate. The abrasion resistance of concretes with various proportions of glass coarse aggregate was first evaluated followed by comparison of their resistance with that of a high-strength mixture typically specified for abrasive coastal environments. Subsequently, the performance of the mixture produced with glass coarse aggregates only was compared with that of limestone coarse aggregates before correlating the abrasion losses suffered by mixtures RC0 and GC12.5 to GC100 with their mechanical properties. Based on the results obtained, it can be concluded that:

1. The use of recycled waste glass in concrete to replace up to $25 \%$ of natural coarse aggregates does not significantly reduce its abrasion performance. However, replacement levels of $50 \%$ and $100 \%$ resulted in a considerable reduction in concrete abrasion resistance. Further, concrete abrasion loss can be predicted from a polynomial function of glass coarse aggregate content.

2. Concretes incorporating up to $25 \%$ recycled waste glass as coarse aggregates exhibited insignificant reductions in abrasion resistance when compared to a high-strength silica fume concrete typically specified for coastal structures situated in abrasive environments. However, the possibility of enhancing the abrasion resistance of glass-aggregate concretes using silica fume requires further investigations.

3. The concrete mixture utilising recycled waste glass only as coarse aggregates exhibited comparable abrasion resistance to that of a mixture with crushed limestone. Therefore, for structures exposed to hydrodynamic abrasion where limestone is proposed as coarse aggregate, recycled waste glass is a possible alternative that also contributes to environmental sustainability and economic savings.

4. Concrete abrasion loss exhibited the highest dependency (99.3 to $99.8 \%$ ) on tensile splitting strength compared to compressive strength and modulus of elasticity at 24,48 and 72 hours. At $95 \%$ confidence however, the relationship between abrasion and tensile splitting strength was only found to be significant at test durations of 48 and 72 hours. This demonstrates tensile strength is a better parameter 
1

2

3

4

\section{ACKNOWLEDGEMENTS}

7 The work presented here forms part of a wider research project by the authors. The authors wish to

for prediction of concrete abrasion loss in the ASTM C1138 test at 48 and 72 hours for glass-aggregate concretes.

5. There is need for further research on the characteristics of the interfacial transition zone of glassaggregate concretes, the hydrodynamic abrasion resistance of high-strength concretes incorporating recycled waste glass as coarse aggregate and the effect of glass aggregate size and shapes.

express their gratitude to the Department of Mechanical, Aerospace and Civil Engineering (MACE), University of Manchester for funding this research. The authors thank Viridor UK for supplying the recycled waste glass aggregates used and CEMEX Ltd for providing the hornfels aggregate. Thanks are also due to Brian Farrington (Belfour Beatty, UK), Paul Nedwell, John Mason and Jorge Arturo Mendoza Ulloa (MACE) for their invaluable assistance with the experimental work.

\section{REFERENCES}

1. Eurostat (2016) Generation of waste by waste category, hazardousness and NACE Rev. 2 activity. http://appsso.eurostat.ec.europa.eu/nui/show.do?lang=en\&dataset=env_wasgen. Accessed 27 Feb 2020

2. Defra (2019) UK Statistics on waste. London

3. US EPA (2017) Facts and figures about materials, waste and recycling. In: Glas. Mater. data. https://www.epa.gov/facts-and-figures-about-materials-waste-and-recycling/glass-materialspecific-data. Accessed 27 Feb 2020

4. ACI Committee 207 (2017) Report on the erosion of concrete in hydraulic structures. American Concrete Institute, Farmington Hills

5. Cunningham LS, Farrington B, Doherty A (2015) Briefing: Abrasion performance of concrete in coastal structures. Proc Inst Civ Eng Marit Eng 168:157-161. https://doi.org/10.1680/jmaen.15.00011 
1 6. BS 6349-1-4 (2013) Maritime works: General - Code of practice for materials. British

2

4

5

6

7

8

9 Standards Institution, London

7. Cunningham L, Robertshaw G, Pomfret M (2012) Blackpool central area coast protection scheme, UK. Proc Inst Civ Eng Marit Eng 165:21-29. https://doi.org/10.1680/maen.2012.165.1.21

8. Cunningham L, Burgess A (2012) Design and construction of the tower headland wave walls, Blackpool, UK. Proc Inst Civ Eng - Civ Eng 165:171-178. https://doi.org/10.1680/cien.12.00007

9. ASTM C1138 (2012) Standard test method for abrasion resistance of concrete (Underwater method ). ASTM International, West Conshohocken

10. Omoding N, Cunningham LS, Lane-Serff GF (2020) Review of concrete resistance to abrasion by waterborne solids. ACI Mater J 117:

11. Topçu IB, Canbaz M (2004) Properties of concrete containing waste glass. Cem Concr Res 34:267-274. https://doi.org/10.1016/j.cemconres.2003.07.003

12. Terro MJ (2006) Properties of concrete made with recycled crushed glass at elevated temperatures. Build Environ 41:633-639. https://doi.org/10.1016/j.buildenv.2005.02.018

13. Serpa D, De Brito J, Pontes J (2015) Concrete made with recycled glass aggregates: Mechanical performance. ACI Mater J 112:29-38. https://doi.org/10.14359/51687366

14. Sangha CM, Alani AM, Walden PJ (2004) Relative strength of green glass cullet concrete. Mag Concr Res 56:293-297

15. Neville AM (1996) Properties of Concrete, 4th ed. Addison Wesley Longman Limited, Essex

16. TS 12143 (2002) Cement Composition and Specification. Turkish Standards Institution, Ankara

17. Dhir RK, Dyer TD, Tang MC (2009) Alkali-silica reaction in concrete containing glass. Mater Struct 42:1451-1462. https://doi.org/10.1617/s11527-008-9465-8 
1 18. Polley C, Cramer SM, de la Cruz R V. (1998) Potential for using waste glass in portland cement concrete. J Mater Civ Eng 10:210-219

19. BS EN 197-1 (2011) Cement. Composition, specifications and conformity criteria for common cements. British Standards Institution, London

20. DIN 52108 (2010) Testing of inorganic non-metallic materials - Wear test using the grinding wheel according to Boehme - Grinding wheel method. DIN

21. BS EN 12620 (2002) Aggregates for concrete. British Standards Institution, London

22. Liu TC (1981) Abrasion resistance of concrete. ACI J 78:341-350

23. Kryžanowski A, Mikoš M, Šušteršič J, Planinc I (2009) Abrasion resistance of concrete in hydraulic structures. ACI Mater J 106:349-356

24. 3D Systems Inc (2013) Sense 3D Scanner. In: User Guid. https://docs.rsonline.com/c26f/0900766b812a6c6c.pdf. Accessed 2 Mar 2020

25. BS EN 12390-3 (2009) Testing hardened concrete. Compressive strength of test specimens. British Standards Institution, London

26. BS EN 12390-6 (2009) Testing hardened concrete. Tensile splitting strength of test specimens. British Standards Institution, London

27. BS EN 12390-13 (2013) Testing hardened concrete. Determination of secant modulus of elasticity in compression. British Standards Institution, London

28. BS EN 1990 (2002) Eurocode - Basis of structural design. British Standards Institution, London

29. Hayter A (2012) Probability and Statistics for Engineers and Scientists, 4th ed. Brooks/Cole, Boston

30. Cross WM, Sabnis KH, Kjerengtroen L, Kellar JJ (2000) Microhardness testing of fiberreinforced cement paste. ACI Mater J 97:162-167

31. Hasparyk NP, Monteiro PJM, Carasek H (2000) Effect of silica fume and rice husk ash on 
alkali-silica reaction. ACI Mater J 97:486-492

32. Ramesh KGB, Sharma UK (2014) Abrasion resistance of concrete containing marginal aggregates. Constr Build Mater 66:712-722. https://doi.org/10.1016/j.conbuildmat.2014.05.084

33. Kang J, Zhang B, Li G (2012) The abrasion-resistance investigation of rubberized concrete. J Wuhan Univ Technol Mater Sci Ed 27:1144-1148. https://doi.org/10.1007/s11595-012-0619-8

34. Horszczaruk E (2005) Abrasion resistance of high-strength concrete in hydraulic structures. Wear 259:62-69. https://doi.org/10.1016/j.wear.2005.02.079

35. Sonebi M, Khayat K (2001) Testing abrasion resistance of high-strength concrete. Cem Concr Aggregates 23:34-43

36. Thomas BS, Kumar S, Mehra P, et al (2016) Abrasion resistance of sustainable green concrete containing waste tire rubber particles. Constr Build Mater 124:906-909. https://doi.org/10.1016/j.conbuildmat.2016.07.110

37. Raphael J (1984) Tensile strength of concrete. ACI J 81:158-165

38. Oloukun FA (1991) Prediction of concrete tensile strength from compressive strength: Evaluation of existing relations for normal weight concrete. ACI Mater J 88:302-309

39. BS EN 1992-1-1 (2004) Eurocode 2 - Design of concrete structures. Part 1-1: General rules and rules for buildings. British Standards Institution, London

40. Noguchi T, Tomosawa F, Nemati KM, et al (2009) A practical equation for elastic modulus of concrete. ACI Struct J 106:690-696

41. Horszczaruk E, Brzozowski P (2017) Effects of fluidal fly ash on abrasion resistance of underwater repair concrete. Wear 376-377:15-21. https://doi.org/10.1016/j.wear.2017.01.051 